\section{UJMM

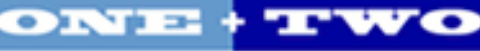

Volume 3 | 2011 Spring

\section{Undergraduate Journal of Mathematical}

Modeling: One + Two

2011

\title{
Arc Length of a Pipe Needed for a Directional Drill
}

\author{
Kenneth Cabana \\ University of South Florida
}

Advisors:

Arcadii Grinshpan, Mathematics and Statistics

Kenneth John Cabana, Cabana Construction of SWFL, Chemical \& Biomedical Engineering Scott Campbell, Chemical \& Biomedical Engineering

Problem Suggested By: Kenneth John Cabana

Follow this and additional works at: https://digitalcommons.usf.edu/ujmm

Part of the Mathematics Commons

UJMM is an open access journal, free to authors and readers, and relies on your support:

Donate Now

\section{Recommended Citation}

Cabana, Kenneth (2011) "Arc Length of a Pipe Needed for a Directional Drill," Undergraduate Journal of Mathematical Modeling: One + Two: Vol. 3: Iss. 2, Article 13.

DOI: http://dx.doi.org/10.5038/2326-3652.3.2.13

Available at: https://digitalcommons.usf.edu/ujmm/vol3/iss2/13 


\title{
Arc Length of a Pipe Needed for a Directional Drill
}

\begin{abstract}
Underground contracting has come a long way in recent years. As communities and buildings are being built, services like water, sewer, and gas are needed to allow people to perform their day to day activities. This research has led to the idea and design of a way to find the arc length of the pipe put into the ground at given points. The pipe length was estimated using the formulas for distance and arc length together with two different modeling methods: Lagrange interpolation and polynomial regression. Both techniques yielded similar results; however this may be situational and in other circumstances their effectiveness may vary.
\end{abstract}

Keywords

Arc Length, Pipe, Directional Drilling

Creative Commons License

(c) (i) (9)

This work is licensed under a Creative Commons Attribution-Noncommercial-Share Alike 4.0 License. 


\section{TABLE OF CONTENTS}

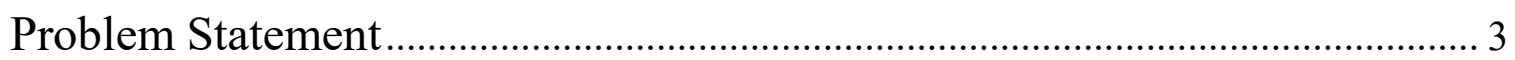

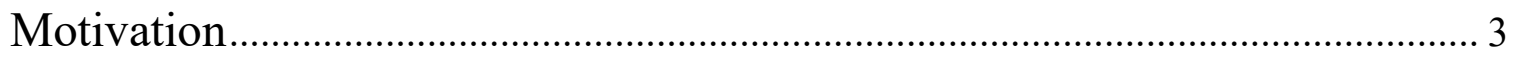

Mathematical Description and Solution Approach ………………………......... 5

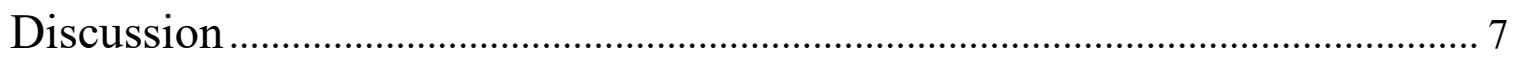

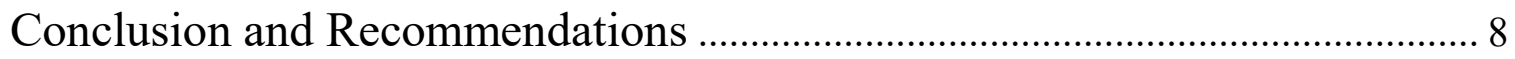

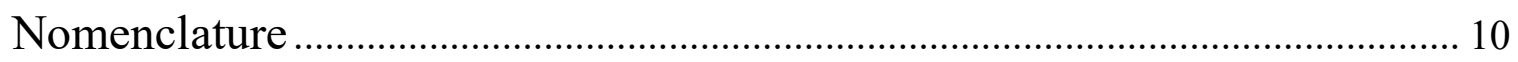

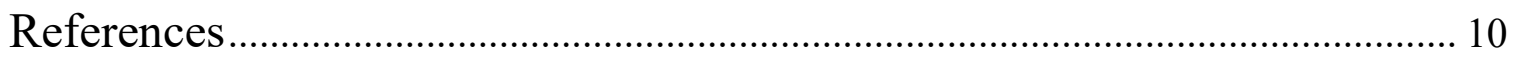

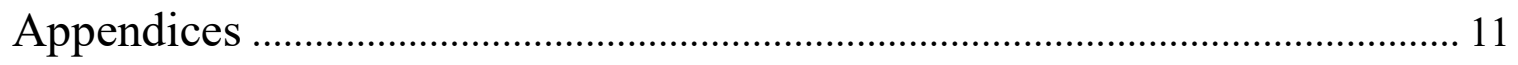




\section{PROBLEM STATEMENT}

Determine the length of pipe needed to perform a directional drill.

\section{MOTIVATION}

Directional drilling is a fairly new concept when putting pipe in the ground. This is a form of trenchless digging and is used most often when digging and putting in pipe the traditional way (open cut) is not possible. Directional drilling is commonly used for drilling under highways and waterways, but may be employed in a variety of circumstances.

The concept behind directional drilling is to drill down into the ground at an angle. Rods are connected together end to end to make the drill stem longer while drilling. The first rod in the ground has a flat angled piece of metal to allow for steering when pushed by the machine. The drill is maneuvered downward until a desired depth is reached. At this point the tooling is aimed back up to the surface in a nice gradual increase, making a parabolic shape. There are a few different ways to track the drill pipe while being underground. The way most commonly used is running a wire through the inside of the drill stem, sending an electric charge through the wire and using a computer to pick up the signal and track it with known Global Positioning System points (GPS). Once the tooling is above ground at the desired

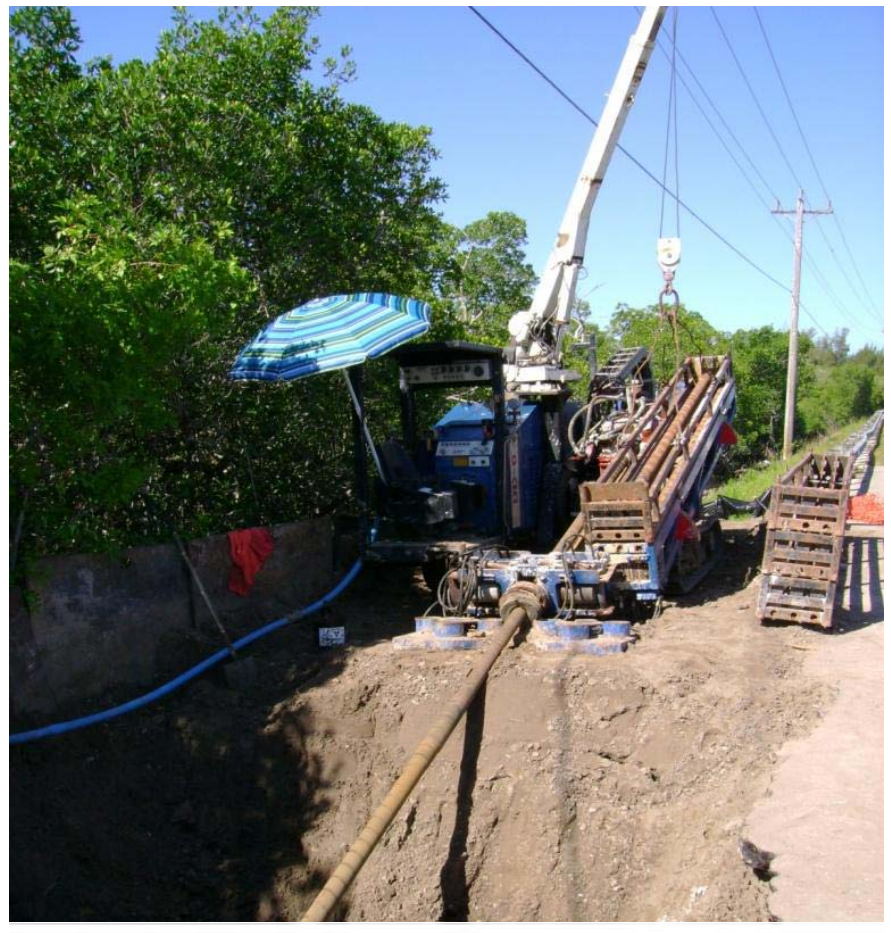

Figure 1: A directional drilling machine with a crane to position the individual drilling rods. 
location, a series of reamers to make the hole bigger will be used. These reamers vary in size and the size correlates with the size of the pipe needed to be put in the ground. As the reamers make the whole bigger, a fluid called bentonite is pumped in through the inside of the drill stem and out the reamer. Bentonite is a mud mixture of several clays and fine sands that acts as a sealer or a frosting so the hole does not collapse.

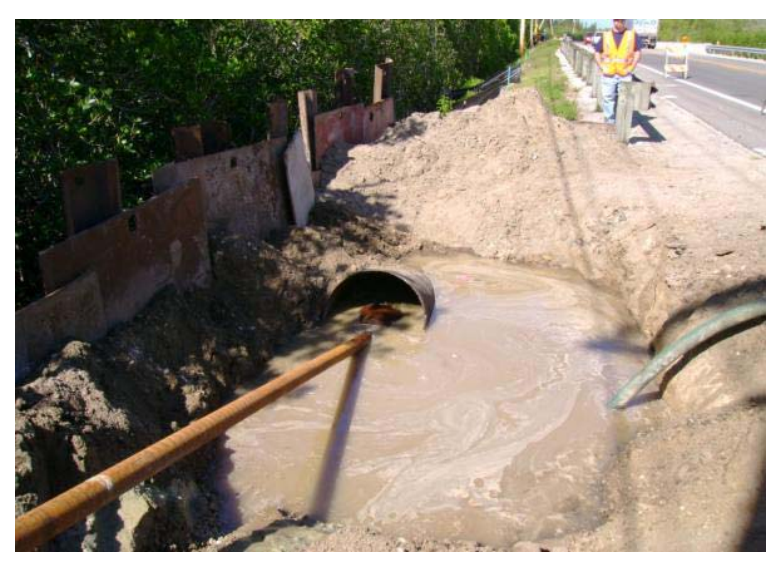

Figure 2: At the entrance the lead rod with the directional end steers the drill.

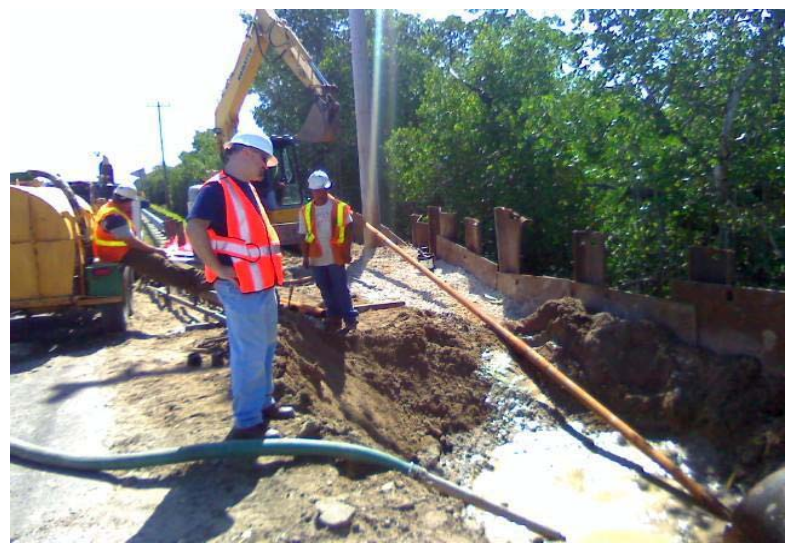

Figure 3: At the exit hole workers are placing a larger diameter reamer to widen the hole to fit the pipe.

Civil engineers design jobs for the underground utility construction companies to install various pipelines which are required for daily living. It is necessary for accurate measurements to be taken when designing and bidding the job as thousands of dollars are on the line for supplies. Poor estimations resulting in having too much or not enough pipe can cost contractors time and money. Since my father is an underground contractor we have a growing interest in the industry. He has a saying when doing direction drills, "You can either win big or lose big". From this research we would like to increase the odds of successful drills. 


\section{MATHEMATICAL DESCRIPTION AND SOLUTION APPROACH}

Given the data in Table 1, we determine the length of pipe needed for the directional drill using three different methods.

\begin{tabular}{|c|ccccccccc|}
\hline Length: & 0 & 25 & 50 & 75 & 100 & 125 & 150 & 175 & 200 \\
\hline Depth: & 0 & -10 & -15 & -20 & -20 & -20 & -15 & -10 & 0 \\
\hline
\end{tabular}

Table 4: Target depths for the directional drill.

The drilling machine is assumed to be located at the Cartesian coordinate $(0,0)$. Suppose the horizontal lengths are $x$-values and the vertical depths below ground level are $y$-values. All distances are recorded in feet.

To get a naïve estimate for the length of pipe needed we first determine the length of the straight line segments connecting the data points in Table 1. This is simply an application of the distance formula in the plane, so we have:

$$
\text { Total Distance }=\sum_{i=1}^{8} \sqrt{\left(x_{i+1}-x_{i}\right)^{2}+\left(y_{i+1}-y_{i}\right)^{2}} \approx 205.83 f t
$$

For our second estimate we employ the method of quadratic regression. We determine the coefficients $\beta_{0}, \beta_{1}$, and $\beta_{2}$ so the function,

$$
f(x)=\beta_{2} x^{2}+\beta_{1} x+\beta_{0}
$$

best fits the data in Table 1. To accomplish this we minimize the distance between the regression curve $f$ and the data with respect to each coefficient $\beta_{0}, \beta_{1}$, and $\beta_{2}$ which gives the following system of equations: 


$$
\begin{aligned}
& \frac{\partial}{\partial \beta_{2}}\left[S\left(\beta_{2}\right)\right]=\frac{\partial}{\partial \beta_{2}}\left[\sum_{i=1}^{9}\left(\left(\beta_{2} x_{i}^{2}+\beta_{1} x_{i}+\beta_{0}\right)-y_{i}\right)^{2}\right]=0 \\
& \frac{\partial}{\partial \beta_{1}}\left[S\left(\beta_{1}\right)\right]=\frac{\partial}{\partial \beta_{1}}\left[\sum_{i=1}^{9}\left(\left(\beta_{2} x_{i}^{2}+\beta_{1} x_{i}+\beta_{0}\right)-y_{i}\right)^{2}\right]=0 \\
& \frac{\partial}{\partial \beta_{0}}\left[S\left(\beta_{0}\right)\right]=\frac{\partial}{\partial \beta_{0}}\left[\sum_{i=1}^{9}\left(\left(\beta_{2} x_{i}{ }^{2}+\beta_{1} x_{i}+\beta_{0}\right)-y_{i}\right)^{2}\right]=0 .
\end{aligned}
$$

Solving this system gives $\beta_{0}=-\frac{100}{33}, \beta_{1}=-\frac{1819}{4620}$, and $\beta_{2}=\frac{79}{39500}$ so the quadratic function which best fits the data from Table 1 is

$$
f(x)=\frac{79}{39500} x^{2}-\frac{1819}{4620} x-\frac{100}{33}
$$

Now to determine the length of pipe needed we calculate the arc length of the function above (4).

We use the well-known formula,

$$
\text { Arc Length }=s=\int_{a}^{b} \sqrt{1+\left[f^{\prime}(x)\right]^{2}} d x
$$

Differentiating (4) and substituting into (5) gives:

$$
s \approx 205.50 \mathrm{ft} \text {. }
$$

The graph of $f$ is pictured below in Chart 5 .

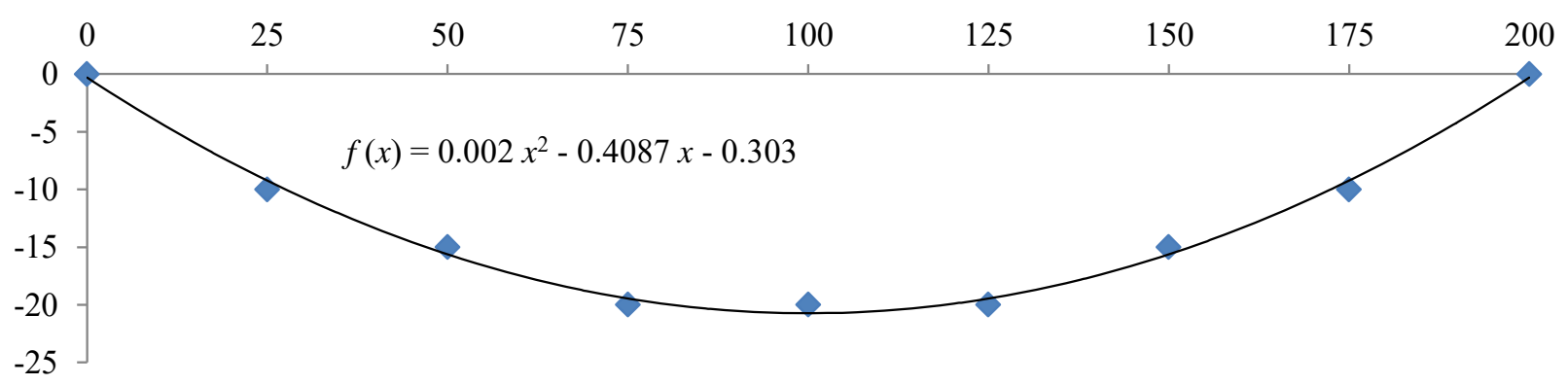

Chart 5: Target drilling depths and quadratic regression line 
For our third and final estimate of the drilling path we use Lagrange interpolation. Given the data points in Table 1, the Lagrange polynomial passing through each of the desired points is of the form:

$$
\begin{gathered}
L(x)=\frac{\left(x-x_{2}\right)\left(x-x_{3}\right) \ldots\left(x-x_{9}\right)}{\left(x_{1}-x_{2}\right)\left(x_{1}-x_{3}\right) \ldots\left(x_{1}-x_{9}\right)} y_{1}+\frac{\left(x-x_{1}\right)\left(x-x_{3}\right) \ldots\left(x-x_{9}\right)}{\left(x_{2}-x_{1}\right)\left(x_{2}-x_{3}\right) \ldots\left(x_{2}-x_{9}\right)} y_{2}+ \\
+\frac{\left(x-x_{1}\right)\left(x-x_{2}\right) \ldots\left(x-x_{8}\right)}{\left(x_{9}-x_{1}\right)\left(x_{9}-x_{3}\right) \ldots\left(x_{9}-x_{8}\right)} y_{9} .
\end{gathered}
$$

Thus the explicit form of our Lagrange polynomial is,

$$
\begin{aligned}
& L(x)=-\frac{1234}{525} x+\frac{1139}{6300} x^{2}-\frac{896}{140625} x^{3}+\frac{136}{1171875} x^{4}-\frac{104}{87890625} x^{5}+\frac{1}{146484375} x^{6}- \\
& \frac{8}{38452148375} x^{7}+\frac{1}{38452148437500} x^{8} .
\end{aligned}
$$

As before we differentiate (8) and substitute into (5) to obtain,

$$
s \approx 213.18 f t
$$

\section{DISCUSSION}

When graphing the coordinate points in Table (Chart 1), the shape of the points was found to be parabolic. This suggests that the quadratic regression function (4) may be a reasonable approximation, but we note that this equation does not pass directly through the given data points. For example, $f(0)=-\frac{100}{3} \approx-33.3 \mathrm{ft}$ rather than zero.

Although distance (piecewise linear) formula passes though each of the collected data points, the linear segments and sharp bends do not match that curve that the drilling machine makes. 
While the Lagrange polynomial achieves both the curvature of the pipe and exactly coincides with the given data, its computation requires more effort than the other two techniques. Even the computation with a few data points requires computer assistance making it impractical for large data sets.

Despite the strengths and weakness of each method, we observe the estimates for the required length of pipe using the distance formula, quadratic regression, and Lagrange interpolation only differed by less than ten feet.

\section{CONCLUSION AND RECOMMENDATIONS}

Finding the arc length of an unknown length of pipe can be achieved by describing the drill path in any of the following three ways: as a piecewise linear function (1), a quadratic function (6) or interpolated as a high order polynomial (9). These three methods relied on distinct methods for modeling the given data points. Since the given lengths and depths of our particular drill path seem parabolic, the quadratic fit is most likely the best fit our data even though it is not the simplest to compute.

The distance formula estimate was quite surprising, in that it closely matched the estimate obtained from the quadratic regression function. However since this method assumes a piecewise linear interpolation function, it may not be reliable when only a few or spread out data points are given. As the distance between the data points decreases, the function begins to conform to the curvature that the machine and pipe will form underground.

Lagrange interpolation produces a high degree polynomial to model the drill path. The extensive computations associated with calculating the interpolation and subsequently finding 
the corresponding arc length make this method unpractical for most real-world situations. Even eight data points yields a polynomial of degree eight. Though the method is straightforward, it is unnecessarily cumbersome to employ when compared to the other two methods. Further, directional drilling is based on accurate estimations, and the actual hole will not match the blueprints exactly. Therefore a model which interpolates the drill path identically is not required.

When directional drilling, the coordinate points highlight a safe path for the operator to follow given a suitable tolerance for error. These points are often created beforehand due to a variety of reasons, e.g., avoiding other buried pipes. An operator may not fully follow the coordinates and can easily venture inches or even feet off course given the circumstances. So we must allow for some flexibility in our model.

The information gained from this research may help underground contracting companies optimize their profits. Some of the techniques that we explored provide a simple way to find the minimum length of pipe needed to fill a hole created through directional drilling. Using a pipe of minimal length will directly translate to a greater profit for the job. Ultimately this preparation and planning will aid the machine operator to drill along the desired path and safely get the pipe into the ground using the least amount of material. 


\title{
NOMENCLATURE
}

\author{
GPS Global Positioning System \\ $\Sigma \quad$ Sum of the Series \\ a Partial Derivative \\ $s \quad$ Arc Length
}

\section{REFERENCES}

Larson, Ron, Robert Hostetler and Bruce Edwards. Calculus. 8th Edition. Boston, MA: Houghton Mifflin Company, 2005.

A Wolfram Research Company. (n.d.). WolframAlpha. Retrieved April 24, 2011, from WolframAlpha: http://www.wolframalpha.com/

Archer, B., \& Weisstein, E. W. (n.d.). Lagrange Interpolating Polynomial . Retrieved April 20, 2011, from MathWorld--A Wolfram Web: http://mathworld.wolfram.com/LagrangeInterpolatingPolynomial.html

Free online Polynomial Calculator . (n.d.). Retrieved April 28, 2011, from xrjunque: http://xrjunque.nom.es/default.aspx

Simmons, B. (n.d.). Mathwords: Terms and Formulas from Beginning Algebra to Calculus . Retrieved April 26, 2011, from MathWords : http://www.mathwords.com/ 


\section{APPENDICES}

\section{$\underline{\text { Appendix A }}$}

Lagrange Expanded formula

$$
\begin{aligned}
& \frac{(x-25)(x-50)(x-75)(x-100)(x-125)(x-150)(x-175)(x-200)}{(0-25)(0-50)(0-75)(0-100)(0-125)(0-150)(0-175)(0-200)}(0) \\
& +\frac{(x-0)(x-25)(x-75)(x-100)(x-125)(x-150)(x-175)(x-200)}{(25-0)(25-50)(25-75)(25-100)(25-125)(25-150)(25-175)(25-200)}(-10) \\
& +\frac{(x-0)(x-25)(x-75)(x-100)(x-125)(x-150)(x-175)(x-200)}{(50-0)(50-25)(50-75)(50-100)(50-125)(50-150)(50-175)(50-200)}(-15) \\
& +\frac{(x-0)(x-25)(x-50)(x-100)(x-125)(x-150)(x-175)(x-200)}{(75-0)(75-25)(75-50)(75-100)(75-125)(75-150)(75-175)(75-200)}(-20) \\
& +\frac{(x-0)(x-25)(x-50)(x-75)(x-125)(x-150)(x-175)(x-200)}{(100-0)(100-25)(100-50)(100-75)(100-125)(100-150)(100-175)(100-200)}(-20) \\
& +\frac{(x-0)(x-25)(x-50)(x-75)(x-100)(x-150)(x-175)(x-200)}{(125-0)(125-25)(125-50)(125-75)(125-100)(125-150)(125-175)(125-200)}(-20) \\
& +\frac{(x-0)(x-25)(x-50)(x-75)(x-100)(x-125)(x-175)(x-200)}{(150-0)(150-25)(150-50)(150-75)(150-100)(150-125)(150-175)(150-200)}(-15) \\
& +\frac{(x-0)(x-25)(x-50)(x-75)(x-100)(x-125)(x-150)(x-200)}{(175-0)(175-25)(175-50)(175-75)(175-100)(175-125)(175-150)(175-200)}(-10) \\
& +\frac{(x-0)(x-25)(x-50)(x-75)(x-100)(x-125)(x-150)(x-200)}{(200-0)(200-25)(200-50)(200-75)(200-100)(200-125)(200-150)(200-175)}(0)
\end{aligned}
$$

\section{$\underline{\text { Appendix B }}$}

$\underline{\text { Wolfram Alpha data input }}$

NIntegrate [Sqrt $\left[1+\left(-(1234 / 525)+1139 / 3150 x-896 / 46875 x^{\wedge} 2+\right.\right.$ $544 / 1171875 x^{\wedge} 3-104 / 17578125 x^{\wedge} 4+2 / 48828125 x^{\wedge} 5$ $\left.\left.\left.8 / 54931640625 x^{\wedge} 6+2 / 9613037109375 x^{\wedge} 7\right)^{\wedge} 2\right],\{x, 0,200\}\right]$

\section{$\underline{\text { Appendix C }}$}

$$
\begin{aligned}
\text { Distance }= & \sqrt{(25-0)^{2}+(10-0)^{2}}+\sqrt{(50-25)^{2}+(15-10)^{2}} \\
& +\sqrt{(75-50)^{2}+(20-15)^{2}}+\sqrt{(100-75)^{2}+(20-20)^{2}} \\
& +\sqrt{(125-100)^{2}+(20-20)^{2}}+\sqrt{(150-125)^{2}+(15-20)^{2}} \\
& +\sqrt{(175-150)^{2}+(10-15)^{2}}+\sqrt{(200-175)^{2}+(0-10)^{2}} \\
= & 205.832 \mathrm{ft}
\end{aligned}
$$

